\title{
PEMBELAJARAN BERMAIN MELALUI RANGSANGAN TINGGI DAN JARAK DITINJAU DARI KECEPATAN
}

\author{
Tri Sutrisno \\ PGSD Universitas Veteran Bangun Nusantara Sukoharjo \\ Email : Triynwasutrisno@gmail.com
}

\begin{abstract}
Absrak
Tujuan penelitian ini untuk mengetahui: (1) Perbedaan pengaruh pembelajaran lompat jauh menggunakan alat bantu tali dan lingkaran sebagai rangsangan tinggi dan jarak secara bertahap terhadap hasil belajar lompat jauh gaya jongkok pada siswa putra kelas IV dan V SD Negeri 3 Sidorejo Bendosari Sukoharjo tahun pelajaran 2018/2019. (2) Perbedaan pengaruh kecepatan tinggi dan rendah terhadap hasil belajar lompat jauh gaya jongkok pada siswa putra kelas IV dan V SD Negeri 3 Sidorejo Bendosari Sukoharjo tahun pelajaran 2018/2019. (3) Ada tidaknya interaksi antara penggunaan alat bantu dan kecepatan terhadap hasil belajar lompat jauh gaya jongkok pada siswa putra kelas IV dan V SD Negeri 1 Kedungrejo Nguntoronadi Wonogiri tahun pelajaran 2008/2009. Penelitian ini menggunakan metode eksperimen. Populasi penelitian ini adalah siswa putra kelas IV dan V SD Negeri 3 Sidorejo Bendosari Sukoharjo tahun pelajaran 2018/2019 berjumlah 20 orang. Dalam penelitian ini dilakukan penelitian populasi. Sampel yang digunakan adalah 10 siswa kategori kecepatan lari tinggi dan 10 siswa kategori kecepatan lari rendah. Teknik pengumpulan data dengan tes dan pengukuran. Data yang dikumpulkan yaitu kecepatan lari dengan lari $40 \mathrm{~m}$, dan kemampuan lompat jauh gaya jongkok. Teknik analisis data yang digunakan adalah ANAVA 2 X 2 dan uji Newman Keuls. Berdasarkan hasil penelitian diperoleh simpulan sebagai berikut: (1) Ada perbedaan pengaruh yang signifikan antara pembelajaran lompat jauh menggunakan alat bantu tali dan lingkaran sebagai rangsangan tiggi dan jarak bertahap terhadap hasil belajar lompat jauh gaya jongkok pada siswa putra kelas IV dan V SD Negeri 3 Sidorejo Bendosari Sukoharjo tahun pelajaran 2018/2019. (2) Ada perbedaan yang signifikan antara siswa kecepatan lari tinggi dan kecepatan lari rendah terhadap hasil belajar lompat jauh gaya jongkok pada siswa putra kelas IV dan V SD Negeri 3 Sidorejo Bendosari Sukoharjo tahun pelajaran 2018/2019. (3) Ada interaksi antara penggunaan alat bantu dan kecepatan terhadap hasil belajar lompat jauh gaya jongkok pada siswa putra kelas IV dan V SD Negeri 3 Sidorejo Bendosari Sukoharjo tahun pelajaran 2018/2019.
\end{abstract}

Kata Kunci : alat bantu, kecepatan, lompat jauh

\begin{abstract}
The purpose of this study was to find out: (1) Differences in the effect of long jump learning using rope and circle aids as high stimuli and gradual distance to learning outcomes squat style long jumps in male students of class IV and V of SD Negeri 3 Sidorejo Bendosari Sukoharjo academic year 2018 / 2019. (2) Difference in the influence of high and low speed on learning outcomes squat style long jump in male students of grade IV and V of SD Negeri 3 Sidorejo Bendosari Sukoharjo academic year 2018/2019.
\end{abstract}


(3) Whether or not there is an interaction between the use of assistive devices and the speed of learning outcomes squat style long jump in male students in grade IV and V of Kedungrejo Nguntoronadi 1 Elementary School in Wonogiri in the academic year 2008/2009. This research is using experimental method. The population of this study were male students of grade IV and V of SD Negeri 3 Sidorejo Bendosari Sukoharjo in the 2018/2019 academic year totaling 20 people. In this study population research was conducted. The sample used was 10 high speed runner students and 10 low running speed categories. Data collection techniques with tests and measurements. The data collected is the speed of running with a $40 \mathrm{~m}$ run, and the squat style long jump ability. The data analysis technique used is ANOVA 2 X 2 and the Newman Keuls test. Based on the results of the study obtained the following conclusions: (1) There is a significant difference between the long jump learning using rope and circle aids as high stimulation and gradual distance to learning outcomes squat style long jump in male students of grade IV and V SD Negeri 3 Sidorejo Bendosari Sukoharjo academic year 2018/2019. (2) There is a significant difference between high running speed students and low running speed towards learning outcomes squat style long jump in male students of grade IV and V of SD Negeri 3 Sidorejo Bendosari Sukoharjo academic year 2018/2019. (3) There is an interaction between the use of assistive devices and the speed of learning outcomes squat style long jump in male students of class IV and V of SD Negeri 3 Sidorejo Bendosari Sukoharjo academic year 2018/2019.

Keywords: tools, speed, long jump

\section{PENDAHULUAN}

Pendidikan jasmani dan kesehatan yang diajarkan di sekolah memiliki peranan sangat penting yaitu, memberikan kesempatan kepada peserta didik untuk terlibat langsung dalam berbagai pengalaman belajar melalui aktivitas jasmani, olahraga dan kesehatan yang terpilih yang dilakukan secara sistematis. Pembekalan pengalaman belajar itu diarahkan untuk membina pertumbuhan fisik dan pengembangan psikis yang lebih baik, sekaligus membentuk pola hidup sehat dan bugar sepanjang hayat.

Pelaksanaan pembelajaran pendidikan jasmani didalamnya diajarkan beberapa macam cabang olahraga yang terangkum kurikulum pendidikan jasmani. Salah satu cabang olahraga yang diajarkan dalam pendidikan jasmani yaitu atletik. Atletik merupakan induk dari semua cabang olahraga yang diajarkan dari sekolah tingkat paling rendah (SD) bahkan Perguruan Tinggi (PT). Seperti dikemukakan Yoyo Bahagia, Ucup Yusuf dan Adang Suherman (2000) bahwa, "atletik merupakan salah satu mata pelajaran pendidikan jasmani kepada siswa dari Sekolah Dasar (SD), Sekolah Lanjutan Tingkat Pertama (SMP) dan Sekolah Lanjutan Tingkat Atas (SLTA)”. 
Seorang guru pendidikan jasmani dan kesehatan untuk mencapai tujuan pembelajaran atletik, harus memperhatikan perkembangan anak, karakteristik anak, kemampuan anak dan kesukaan anak serta tujuan yang harus di capai. Cabang olahraga atletik didalamnya terdiri dari empat nomor utama yaitu jalan, lari dan lempar. Dari setiap nomor tersebut didalamnya terdapat beberapa nomor yang diperlombakan. Untuk nomor lari terdiri atas: lari jarak pendek, jarak menengah, jarak jauh atau marathon, lari gawang, lari sambung, dan lari cross county. Nomor lompat meliputi: lompat jauh, lompat tinggi, lompat jangkit, lompat tinggi galah. Nomor lempar meliputi lempar cakram, lempar lembing, tolak peluru dan lontr martil.

Anak tidak pada tempatnya bila mereka dilatih untuk mencapai prestasi tinggi dalam olahraga tetapi sebaliknya mereka harus dibimbing sesuai dengan kemampuannya. Seperti yang dikemukakan Djumidar (2007) "dalam pengajaran pendidikan jasmani di sekolah dasar harus disesuaikan dengan tingkat kemampuan siswa baik ditinjau dari segi fisik maupun ditinjau dari segi mental”.

Berdasarkan observasi dibeberapa SD di kecamatan Bendosari kabupaten Sukoharjo pada tahun 2018, dapat diketahui bahwa masih banyak guru pendidikan jasmani kesehatan dan rekreasi di dalam pembelajaran atletik cenderung pada penguasaan teknik dan prestasi, sehingga banyak siswa SD yang tidak berminat atau tidak tertarik pada cabang olahraga atletik tersebut. Akibat tidak berminat dan kurang tertarik banyak siswa enggan untuk mengikuti tambahan atau ekstrakurikuler pada cabang ini.

Selanjutnya menurut Djumidar (2007) "dunia anak lebih dekat dengan situasi permainan dari pada yang serius, di dalam pembelajaran disajikan banyak variasi-variasi agar supaya tidak mudah jenuh sebab siswa kerap kali juga cepat bosan melaksanakan kegiatannya”.

Model bermain, dimaksudkan untuk mengembangkan aspek-aspek kemampuan motorik melalui aktivitas bermain yang variatif, berjenjang tingkat kesulitannya. Menurut Yudha M. Saputra (2001) "permainan atletik merupakan kombinasi antara kegembiraan gerak dan tantangan tugas gerak yang dekat dengan pengalaman nyata". Dengan demikian guru dapat memanfaatkan bermain 
ini untuk memotivasi siswa melakukan lompat jauh gaya jongkok dengan memberikan materi yang merangsang untuk bermain, yaitu menggunakan tali sebagai rangsangan tingi dan lingkaran sebagai rangsangan jarak.

Pembelajaran lompat menggunakan alat bantu tali dan lingkaran sebagai rangsangan tinggi dan jarak merupakan bentuk pembelajaran lompat jauh yang bertujuan untuk merangsang siswa agar mampu melompat sejauh-jauhnya. Namun dari kedua bentuk pembelajaran tersebut belum diketahui efektivitasnya, karena masing-masing pembelajaran tersebut memiliki kelebihan dan kelemahan, sehingga belum diketahui pembelajaran mana yang lebih baik pengaruhnya terhadap hasil belajar lompat jauh gaya jongkok.

Pembelajaran lompat jauh menggunakan alat bantu tali dan lingkaran sebagai rangsangan tinggi dan jarak bertujuan meningkatan pencapaian lompatan yang sejauh-jauhnya. Di sisi lain juga bertujuan untuk mengembangkan penguasaan teknik lompat jauh gaya jongkok. Namun demikian, lompatan dapat dicapai sejauh-jauhnya tidak hanya dipengaruhi pembelajaran yang baik dan terprogram tetapi juga kecepatan merupakan unsur penting dalam lompat jauh seperti yang diungkapkan Soedarminto (2004) "pada lompat jauh, kecepatan awalan meupakan faktor yang penting guna mengembangkan daya pada waktu bertolak'. Permasalahan yang telah dikemukakan di atas yang melatar belakangi judul penelitian, "Perbedaan Pengaruh Pembelajaran Bermain Menggunakan Rangsangan Tinggi,Jarak Dan Kecepatan Terhadap Hasil Belajar Lompat Jauh Gaya Jongkok Pada Siswa Putra Kelas IV dan V SD Negeri 3 Sidorejo Bendosari Sukoharjo tahun pelajaran 2018/2019',

\section{METODE PENELITIAN}

Metode yang digunakan dalam penelitian ini adalah metode eksperimen. Sugiyanto (1994) menyatakan "Tujuan penelitian eksperimental adalah untuk meneliti ada tidaknya hubungan sebab akibat serta besarnya hubungan sebab akibat tersebut dengan cara memberikan perlakuan (treatment) terhadap kelompok 
eksperimen yang hasilnya dibandingkan dengan hasil kelompok kontrol yang tidak diberikan perlakuan atau diberi perlakukan yang berbeda".

Rancangan penelitian yang digunakan adalah anava faktorial 2 X 2 . Menurut Sugiyanto (1994) bahwa, "Rancangan faktorial adalah rancangan dimana bisa dimasukkan dua variabel atau lebih untuk memanipulasi secara simultan. Dengan rancangan ini bisa diteliti pengaruh setiap variabel independen terhadap variabel dependen, dan juga pengaruh interaksi antara variabel-variabel independen". Untuk lebih jelasnya berikut ini disajikan gambar rancangan penelitian ini sebagai berikut :

Tabel 1. Anava $2 \times 2$ penelitian

\begin{tabular}{lcc}
\hline Pembelajaran Lompat Jauh & $\begin{array}{c}\text { Menggunakan Tali } \\
\left(\mathrm{A}_{1}\right)\end{array}$ & $\begin{array}{c}\text { Menggunakan } \\
\text { Lingkaran } \\
\left(\mathrm{A}_{2}\right)\end{array}$ \\
\hline Kecepatan & $\mathrm{A}_{1} \mathrm{~B}_{1}$ & $\mathrm{~A}_{2} \mathrm{~B}_{1}$ \\
Renggi $\left(\mathrm{B}_{1}\right)$ & $\mathrm{A}_{1} \mathrm{~B}_{2}$ & $\mathrm{~A}_{2} \mathrm{~B}_{2}$ \\
\hline
\end{tabular}

Keterangan :

$\mathrm{A}_{1} \mathrm{~B}_{1}$ : Kelompok pembelajaran lompat jauh gaya jongkok menggunakan tali dengan kriteria sampel kecepatan tinggi.

$\mathrm{A}_{1} \mathrm{~B}_{2}$ : Kelompok pembelajaran lompat jauh gaya jongkok menggunakan tali dengan kriteria sampel kecepatan rendah.

$\mathrm{A}_{2} \mathrm{~B}_{1}$ : Kelompok pembelajaran lompat jauh gaya jongkok menggunakan lingkaran dengan kriteria sampel kecepatan tinggi.

$\mathrm{A}_{2} \mathrm{~B}_{2}$ : Kelompok pembelajaran lompat jauh gaya jongkok menggunakan lingkaran dengan kriteria sampel kecepatan rendah.

\section{HASIL DAN PEMBAHASAN}

Pembahasan hasil penlitian ini memberikan penafsiran lebih lanjut mengenai hasil-hasil analisis data yang telah dilakukan sebelumnya.

\section{Pengaruh Pembelajaran Menggunaan Alat Bantu Tali Dan Lingkaran Terhadap Hasil Belajar Lompat Jauh Gaya Jongkok}

Berdasarkan pengujian hipotesis pertama menunjukkan bahwa, ada perbedaan pengaruh antara pembelajaran lompat jauh menggunakan tali dan lingkaran terhadap hasil belajar lompat jauh gaya jongkok siswa putra kelas IV dan V SD Negeri 3 Sidorejo Bendosari Sukoharjo tahun pelajaran 2018/2019. Pada kelompok siswa yang diberi perlakuan pembelajaran lompat 
jauh menggunakan tali mempunyai peningkatan yang lebih baik terhadap kemampuan lompat jauh gaya jongkok dibandingkan dengan kelompok siswa yang diberi perlakuan pembelajaran lompat jauh menggunakan lingkaran. Hal ini karena, siswa dituntut untuk melompati tali yang dibentangkan dengan ketinggian tertentu, sehingga lompatan harus dilakukan setinggi mungkin agar tidak menyentuh atau menabrak tali tersebut. Lompatan yang tinggi akan dapat mendukung penguasan teknik melayang yaitu untuk membuat posisi jongkok. Namun sebaliknya, pada pembelajaran lompat jauh gaya jongkok menggunakan lingkaran ada kecenderungan untuk melompat sejauh-jauhnya dan teknik melayang di udara sedikit terabaikan.

Berdasarkan hasil perhitungan yang telah dilakukan diperoleh nilai $\mathrm{F}_{0}$ sebesar 8572. $170>\mathrm{F}_{\mathrm{t}}$ 4.490, pada kelompok yang diberi perlakuan menggunakan alat bantu tali mempunyai peningkatan lebi baik dibandingkan dengan kelompok siswa yang diberi perlakuan menggunakan alat bantu lingkaran, dengan nilai rata-rata peningkatan 0.330 dan 0.325. Dengan demikian hipotesis yang menyatakan, ada perbedaan pengaruh pembelajaran menggunaan alat bantu tali dan lingkaran terhadap hasil belajar lompat jauh gaya jongkok pada siswa putra kelas IV dan V SD Negeri 3 Sidorejo Bendosari Sukoharjo tahun pelajaran 2018/2019dapat diterima kebenaranya.

\section{Pengaruh Antara Kecepatan Lari Tinggi Dan Kecepatan Lari Rendah} Terhadap Hasil Belajar Lompat Jauh Gaya Jongkok

Berdasarkan pengujian hipotesis kedua menunjukkan bahwa, ada Perbedaan yang signifikan antara kecepatan lari tinggi dan kecepatan lari rendah terhadap hasil belajar lompat jauh gaya jongkok siswa putra kelas IV dan V SD Negeri 3 Sidorejo Bendosari Sukoharjo tahun pelajaran 2018/2019. Siswa yang memiliki kecepatan lari tinggi mempunyai kemampuan lompat jauh gaya jongkok yang lebih baik daripada siswa yang memiliki kecepatan lari rendah. 
Berdasarkan hasil perhitungan yang telah dilakukan diperoleh nilai $\mathrm{F}_{0}$ $17078.224>\mathrm{F}_{\mathrm{t}} \quad$ 4.490, rata-rata peningkatan siswa yang mempunyai kecepatan lari tinggi 0.350 lebih baik dibandingkan siswa yang mempunyai kecepatan lari rendah sebesar 0.305. Dengan demikian hipotesis yang menyatakan, ada perbedaan pengaruh antara kecepatan tinggi dan kecepatan rendah terhadap hasil belajar lompat jauh gaya jongkok pada siswa putra kelas IV dan V SD Negeri 3 Sidorejo Bendosari Sukoharjo tahun pelajaran 2018/2019 dapat diterima kebenarannya.

\section{Interaksi Antara Penggunaan Alat Bantu Dan Kecepatan Lari Terhadap} Hasil Belajar Lompat Jauh Gaya Jongkok

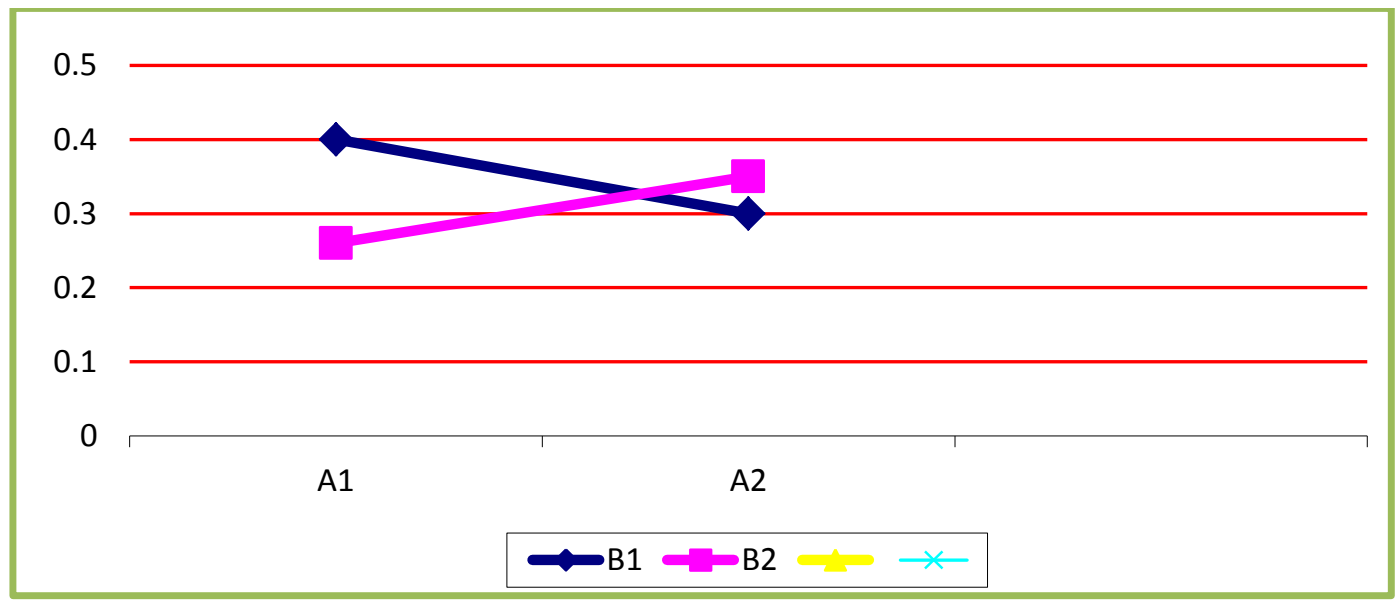

Gambar 2. Bentuk Interaksi Penggunaan Alat Bantu Lompat Jauh Dan Kecepatan Lari

Berdasarkan gambar 2. Menunjukkan bahwa, bentuk garis perubahan besarnya nilai peningkatan hasil belajar lompat jauh gaya jongkok yaitu berpotongan. Hal ini menunjukkan ada interaksi antara penggunaan alat bantu dalam pembelajaran lompat jauh gaya jongkok dan kecepatan lari.

Berdasarkan hasil analisis data nilai $\mathrm{F}_{0}=25617.300$ ternyata lebih besar dari $\mathrm{F}_{\mathrm{t}}=4.490\left(\mathrm{~F}_{0}>\mathrm{F}_{\mathrm{t}}\right)$ pada taraf signifikansi 5\%. Hal ini menunjukkan bahwa antara keduanya ada interaksi. Dengan demikian, hipotesis yang menyatakan ada interaksi antara penggunaan alat bantu tali dan lingkaran dengan kecepatan lari terhadap hasil belajar lompat jauh gaya jongkok pada siswa putra 
kelas IV dan V SD Negeri 3 Sidorejo Bendosari Sukoharjo tahun pelajaran 2018/2019 dapat diterima kebenarannya.

\section{SIMPULAN}

Berdasarkan analisis data dan pembahasanya yang telah diungkapkan, maka dapat ditarik simpulan sebagai berikut:

1. Ada perbedaan pengaruh pembelajaran lompat jauh menggunakan alat bantu tali dan lingkaran sebagai rangsangan tiggi dan jarak bertahap terhadap hasil belajar lompat jauh gaya jongkok pada siswa putra kelas IV dan V SD Negeri 3 Sidorejo Bendosari Sukoharjo tahun pelajaran 2018/2019. Dari analisis data menjukkan $\mathrm{F}_{0}=8572.170>$ dari $\mathrm{F}_{\mathrm{t}}=4.490$. Pengaruh yang ditimbulkan dari pembelajaran menggunakan alat bantu tali lebih baik daripada menggunakan alat bantu lingkaran dengan rata-rata peningkatanya 0.330 dan 0.325 .

2. Ada perbedaan pengaruh antara kecepatan tinggi dan kecepatan rendah terhadap hasil belajar lompat jauh gaya jongkok pada siswa putra kelas IV dan V SD Negeri 3 Sidorejo Bendosari Sukoharjo tahun pelajaran 2018/2019. Dari analisis data menjukkan $F_{0}=17078.224>$ dari $F_{t}=4.490$. pengaruh yang ditimbulkan oleh siswa kecepatan lari tinggi lebih baik dibandingkan siswa kecepatan lari rendah dengan rata-rata peningkatanya 0.350 dan 0.305.

3. Ada interaksi antara penggunaan alat bantu dan kecepatan terhadap hasil belajar lompat jauh gaya jongkok pada siswa putra kelas IV dan V SD Negeri 3 Sidorejo Bendosari Sukoharjo tahun pelajaran 2018/2019. Dari analisis data menjukkan $\mathrm{F}_{0}=25617.300>\mathrm{F}_{\mathrm{t}}=4.490$.

a. Penggunaan alat bantu tali lebih cocok untuk kecepatan lari tinggi.

b. Penggunaan alat bantu lingkaran lebih cocok untuk kecepatan lari rendah.

\section{DAFTAR PUSTAKA}

A. Hamidsyah Noer. 1996. Ilmu Kepelatihan Lanjut. Surakarta: UNS Press. 
Aip Syarifuddin. 1992. Atletik. Jakarta: Departemen Pendidikan dan Kebudayaan. Direktorat Jenderal Pendidikan Tinggi. Proyek Pembinaan Tenaga Kependidikan.

Barry L. Johnson dan Jack K. Nelson 1986. Practical Measurement For Evaluation Pysical Education. Minesota USA: Publishing Company.

Depdiknas. 2007/2008. Kurikulum Tingkat Satuan Pendidikan Standart Kompetensi dan Kompetensi Dasar Pendidikan Jamsni, Olahraga dan Kesehatan. Jakarta: Depdiknas.

H.J. Gino, Suwarni, Suripto, Maryanto dan Sutijan. 1998. Belajar dan Pembelajaran II. Surakarta: UNS Press.

Jess Jarver. 1999. Belajar dan Berlatih Atletik. Alih Bahasa. BE. Handoko. Bandung: Pioner Jaya.

Jonath U., Haag E., \& Krempel R. 1987. Atletik I. Alih Bahasa Suparno. Jakarta: PT. Rosda Jaya Putra.

Mochamad Djumidar A. Widya. 2004. Belajar Berlatih Gerak-Gerak Dasar Atletik dalam Bermain. Jakarta. PT. Raja Grafindo Persada.

M. Sajoto. 1995. Pembinaan Kondisi Fisik Dalam Olahraga. Semarang: IKIP Semarang Press.

Rusli Lutan. 1988. Belajar Ketrampilan Motorik Pengantar Teori dan Metode. Jakarta: Depdikbud. Dirjendikti.

Sudjana. 1994. Metoda Statistika. Bandung: Tarsito.

Sudjarwo. 1993. Ilmu Kepelatihan Dasar. Surakarta: UNS Press.

Sugiyanto. 1995. Metodologi Penelitian. Surakarta: UNS Press.

Suharno HP. 1993. Metodologi Pelatihan. Yogyakarta: IKIP Yogyakarta.

Sukintaka. 2004. Teori Pendidikan Jasmani Filosofi Pembelajaran dan Masa Depan. Bandung: Yayasan Nuansa Cendekia.

Tamsir Riyadi. 1985. Petunjuk Atletik. Yogyakarta: IKIP Yogyakarta.

Yoyo Bahagia, Ucup Yusuf dan Adang Suherman. 1999/2000. Atletik.

Depdikbud. Direktorat Jenderal Pendidikan Dasar dan Menengah Bagian Proyek Penataran Guru SMP Setara DIII 